\title{
Afrikaanse oorlogspoësie na Sestig II ${ }^{1}$
}

\begin{abstract}
In this, the second and final article on the study of Afrikaans poetry dealing with aspects of the South African war since the Sixties, an assessment is made of the moral stance adopted by poets vis-à-vis the conflict, while the main characteristics of the war poetry of this period are contrasted with those of the period preceding it.
\end{abstract}

\section{Digterlike stellingnames teenoor die oorlog}

Oor die Suid-Afrikaanse militêre konflik is daar nie net gerapporteer nie. Iets wat in die 'digterlike berigte te velde' opval, is die groot hoeveelheid gedigte waarin digters stelling inneem, of 'n persoonlike stellingname laat blyk, teenoor die oorlog as sodanig of teenoor een of albei van die deelnemende partye. Dit is nie vreemd nie, gesien die morele probleem waarvoor die oorlog die digters gestel het. Enersyds is daar die besef dat daar ' $n$ stuk onverdedigbaarheid in die heersende landsbeleid (die primêre oorsaak van die konflik) sit as gevolg van die diskriminerende element daarin; andersyds die besef van wat alles verlore sal gaan as die aanslag teen die status quo sou moes slaag. Die gevolg was digterlike stellingnames, op die basis van moraliteit, van 'n omvang wat haas onbekend was in die Afrikaanse poësie tot op daardie tydstip.

\subsection{Wye spektrum van stellingnames}

Die stellingnames bestryk 'n wye spektrum. Dit strek vanaf 'n gees van onverskilligheid, selfs van totale onbetrokkenheid by die gebeurtenisse waarby die digter, byvoorbeeld as digterlike verslaggewer of as soldaat, veronderstel is om betrokke te wees, tot aan solidariteit met een van die twee strydende partye.

1 Hicrdic artikel is 'n vervolg op dic antikel in Literator, 15(1) 1994:73-96 
Johan Lodewyk Marais verteenwoordig die pasifistiese pool van die spektrum. "Ek skryf alles om vrede te bewaar / in jou, Azanië, ons moederland / en geboorteland", verklaar hy in "Alternatief" (1983:39). In "op pad na die grens" neem hy hom voor:

wys die Pro Patria van die hand

en die bronsbeeldjie

en die grootkoppe

om my veldse graf

(Marais, 1983:47),

terwyl hy "In wyer verband" versug:

Ek wens ek was 'n ruitewasser

en niks meer nie ...

Here, maak my 'n ruitewasser

(Marais, 1989:70).

André Letoit (1988) en Johan van Wyk (1981) staan ná hieraan. Annesu de Vos se onbetrokkenheid is egter van 'n slagvaardiger allure. "Wanneer die drie-uurSondagtromme 'n opstaantyd aankondig", verklaar sy, sal sy haar omdraai en verder slaap, want

te lank het ek my laat pynig ...

boek gehou van die kwaad

my bed benat oor die bedroë land

bereken:

die debiete en krediete

van hoeveel ons/hulle skuld

en hoeveel ons/hulle haat

(De Vos, 1982:12/13).

Ook Wilma Stockenström is teen geweld, en daarom ook teen oorlog, gekant. Die mees obsene van alle oorloë is vir haar die huursoldaatoorlog, waarvoor die kwalifikasies "diverse littekens" is -

vliesige herinnerings aan Kuba en Katanga

en op die voorkop die Biafraanse Kaïnsmerk

(Stockenström, 1973:50).

Tog is sy bereid om haar vir ' $n$ bepaalde vorm van oorlogsdiens aan te meld: om opleiding in noodhulp te verskaf. Wanneer sy egter die gewondes verpleeg, sal sy sielsdeursoekende vrae aan hulle stel: 
"Hoekom het jy 'n huis gebou?

het jy leer lees?"

Hoekom

Maar sy sal dié soort vraag ook aan haarself stel:

... Vir wie troos jou hande?

As daar geen brood meer is om te bak, waarvoor spalk en verbind julle dan nog, hande, wat te veel leer doen het?

(Stockenström, 1970:44).

Die meeste digters laat egter ' $n$ besliste betrokkenheid in die vorm van ' $n$ simpatieke ingesteldheid teenoor een of die ander van die twee strydende partye blyk. Daar is weinig pogings om die stryd sub specie aeternitatis te sien, dit wil sê om die mate van 'gelyk' van álbei opponente te probeer evalueer. W.E.G. Louw is een van die uitsonderings, hoewel sy simpatie beslis by een party lê. Hy is sterk bewus van die aandeel van sy mense aan die euwel van ongelyke behandeling en minagting van menswaardigheid wat die grondoorsaak van die oorlog was. Soos 'n Ou-Testamentiese profeet meet hy die straf ongekompromitteerd toe, veral in Naggesprek (1972). Hy is egter diep bewus van wat alles verlore sal gaan as die bestel met geweld ten onder gebring moet word.

Die skerpioen-patrollie deurkruis die nag;

aan ons grense staan soldate wag...

Maar wie bewaar wat ons opgegaar

en naarstig gebou het oor driehonderd jaar?

(Louw, 1976:19)

Daarom die bekommerde vrae, nie net vanuit 'n plaaslike perspektief nie, maar ook vanuit ' $n$ algemeen-Westerse:

... draai die radarantenne? Is die skerms skoon?

Staan die stralers gereed om op te styg?

Want soos sprinkane sal die swerms kom die rooies, die geles, die bruines en swartes; maar nog vóór die tenks, die kanonne, mortiere, as die sterrereën van missiele stort wie weet, sal wolke soos paddastoele opbloei en oor ons stede vlam

(Louw, 1976:20).

Daar is egter ook die gerusstellende wete: 
hoe lank ons staande sal bly, weet niemand

maar die klipmuur is vervang deur staal

die snaphaan deur impala en ratel ...

Ons is nie kleingeld in julle sakke!

(Louw, 1980:16).

Emst van Heerden, nes enkele ander digters, se posisie is meer ambivalent Enersyds is hy hom bewus van die bedreigde posisie waarin kosbaarhede waaraan hy waarde heg, beland het as gevolg van die aanslag daarop - dit geld veral sy taal - , maar andersyds is hy net so bewus van die onvermydelikheid, maar veral van die geregverdigdheid van die aanslag. Immers:

Deur rye grafte word die land beskaaf, met stewels, Casspirs, bandeliers ' $n$ hele menseras in traangas ingedwing. die eiland-gevangenis word ' $n$ dyk waarteen 'n see in opstand kom

(Van Heerden, 1987:27).

\subsection{Simpatie met vegters teen die bestel}

Die meeste digters se simpatie lê by die vegters teen die bestel.

Die swaartepunt in digterlike houding het dus ingrypend verskuif sedert die voorSestigerjare. In die poësie van die geslagte voor Sestig was die digters byna sonder uitsondering aan 'die Afrikanerkant' van die stryd, wat nie noodwendig dieselfde as 'die Regeringskant' was nie. Dink byvoorbeeld, wat laasgenoemde aspek betref, aan Leipoldt se 'afwykende' lojaliteit gedurende die Eerste en Tweede Wêreldoorloë en dié van Uys Krige gedurende laasgenoemde oorlog.

Fanie Olivier se bundel Verklarings 1967-1987, 'n versameling van sy kontesterende gedigte oor twee dekades heen, open met 'n "handboek vir opstandsvegters", met as ondertitel: "[na mao]". Hierin betuig hy solidariteit met die vryheidsvegters.

D.P.M. Botes vra dat sy land se vergryp teen 'n geregverdige vryheidstryd in herinnering gebring moet word:

sê aan vryheid

dat my land se vryheidshelde in tronke sit

dat die nag ingesypel het oor die dag

dat my mense treurig is

dat sy leiers wette verbreek met hulle wette ... 
sê aan hom dat ons buite wag

en dit het reeds begin reën

(Botes, 1973:52).

In "Boeta Boer" kondoneer P.J. Philander klipgooiery op 'n fyn-verdoeselde manier:

In hierdie stryd teen jou, boeta Boer,

laat ons geen klip onaangeroer

(Philander, 1986:71).

In "valuta" laat hy egter onverdoeseld blyk waar sy steun lê:

Daagliks met lokasiebrande

verneder ons jou Krugerrande

en laat jou sakelui met hul goue ringe

handdrukke soek in die ANC se binnekringe

(Philander, 1986:73).

Breyten Breytenbach se poësie was van die begin af nie op kritiek op die bestel gerig nie, maar op die vernietiging daarvan. Die twee slotafdelings van Kouevuur, waarvan die eerste die subtitel "verse te velde" dra, is vir ' $n$ belangrike gedeelte ' $n$ handboek vir vryheidsvegters. Daar is meer as speelsheid opgeslote in die slotwoorde van sy gedig vir sy ma, "Die hand vol vere":

slaap gerus met die een oor oop:

anders as ou Dog

waar ék 'n veertjie plant

kom 'n kêk-kôk hoender op

(Breytenbach, 1969:68),

sowel as in die vermelding van die feit dat daar ook geweerdraers in sy entourage sal wees. Na sy tronkervaring het die besef ingetree dat handtastelikheid ("nie met die pen nie, maar met die masjiengeweer"), wat hom persoonlik betref, nie die oplossing is nie, hoewel hy die onvermydelikheid van die bloedoffer in die stryd besef. Tog kan die neiging tot kondonering van geweld by tyd en geleentheid nie heeltemal onderdruk word nie. In werklikheid vind dit in sy voorlaaste bundel, soos die so, die mees onverhulde uitdrukking in sy hele werk tot op datum:

Godseblief, góói dan die gif in die wit varke met die kneukelharsings se melk!

(“12 Maart 1974” - Breytenbach, 1990:79). 


\subsection{Visie op die einde van stryd}

Sommige digters se kantkies na die een of die ander kant blyk veral uit hul visie van hoe hulle meen die stryd gaan eindig.

Vir Etienne van Heerden verdien die vryheidsvegters sy lojaliteit want dis hulle wat die aanbreek van 'n nuwe tydvak moontlik gemaak het (dit wil sê profeties gesien). Sy eie volk, "nou deur die dood getem", behoort saam aan die bevrydingsfees deel te neem, omdat die bevryding van die land ook 'n bevryding van hulself was ("The day after" - Van Heerden, 1987:91).

Fanie Olivier deel hierdie visie:

lank ná die reēn

reën dit nog in die bome

en meen hy te weet

.... hoe soet

die land gaan uitblom hoe hoog

die gras hierna sal staan

(Olivier, 1988:61).

'n Paar digters wat die kant van die vryheidsvegters gekies het, gaan nog verder as simpatie: hulle stel hul digkuns aktief in diens van die stryd.

Fanie Olivier stuur byvoorbeeld 'n "bombouquet" aan die Staatspresident (1988: 12). Sy doel is om met sy gedigte die bestel tot in sy fondamente te skud.

Breyten Breytenbach was van vroeg af bewus van die krag van die gedig as wapen in die stryd. Hy het die meeste strydgedigte van al die digters gelewer. Welbeskou is dit gedigte met ' $n$ nogal beperkte effektiwiteit as strydpoësie. Dis swaar met intellektuele materiaal gelaai (esoteriese verwysings na historiese, politieke en sosiale toedragte elders ter wêreld), die taal is ongewoon genuanseerd, terwyl konsepte dikwels in ingewikkelde beeldfigure opgaan. Dis wesenlik oorlogspoësie vir die gesofistikeerde enkeling, nie vir 'n massabevrydingsbeweging nie. Dit blyk duidelik uit wat hy oor die funksie van die gedig skryf (metapoësie), ook oor die aard van die strydgedig, soos die slotgedig in soos die so, "31 Desember 1988", waarin hy sy werkswyse en doel karakteriseer as 'n versigtige spel

van woord na woord om die skuiwe te snoer en in die voeë te skuil of 'n kop bo water te hou

(Breytenbach, 1990:202). 
Tog bevat die bundel ook sy mees effektiewe strydgedig: "5 Februarie 1974", met as onderskrif: "boeke is bomme, vir my dooie broer, Abraham", geskryf na aanleiding van die briefbommoord op die swart aktivis Abraham Tiro. 'n Verteller deel die besonderhede van Tiro se lewensloop en dood mee, terwyl 'n koor na elke besonderheid die refreinreël "en Tiro lê in sy eie bloed" herhaal, tot dit op die einde verdubbel word en daar boonop 'n slotreêl toegevoeg word wat daarop varieer, en die relaas so tot 'n hoogtepunt voer:

en Tiro is die binnevlam binne die rooi.

Saamgelees met die onderskrif, beteken dit dat die bloed gedig geword het, wat dieselfde funksie as bloed sal hê, te wete vuurmaakhout vir die rewolusie.

Van al die digters het Daniël Hugo hom die omvangrykste verantwoord wat die bydrae wat die gedig tot die stryd kan lewer, betref. Aan die tuisfront lewer die digter sy bydrae so goed as wat die soldaat dit aan die oorlogsfront doen:

in plaas van loodswaar die pistool

hou ek ' $n$ potlood in my hand

(“Aan die tuisfront" - Hugo, 1983:12).

Die woord mag broos wees, maar dis kosbare "breekware vir die rewolusie"

Sy huilende baba bring vir hom die insig dat meer as kritiek op die bestel nodig is:

\author{
moes die verset alleen maar verse skryf \\ sonder die knal en bloed van 'n bom \\ wie sou onreg vermoed? \\ so verskaf die klein Hugo se skril geskree \\ begrip vir die harde geweld van die ANC
}

(Hugo, 1983:25).

Daarom kan hy die kontesterende digter as "rymguerilla" tipeer (Hugo, 1983:24).

Tog is hy hom bewus van die ongelyke bydrae van potlood en geweer, omdat die potlood hom moet voeg na 'n tug wat die geweer nie ken nie: dié van die wette van die kuns.

geen digter se bevel

sal die mars tot stilstand

bring - ook al is hy

'n eerste luitenant 
sy outoriteit is $\mathrm{min}$

maar as hy 'n rymklank

roep, markeer die tyd die pas

'n oomblik lank

(Hugo, 1984:29).

Hierdie pasvertraging van die stryd deur die kuns is egter vir die rewolusie onbehaaglik:

... waaragtig rewolusionêr is die tyd

en 'n reaksionêr elkeen wat hom wil stuit -

dit verdoem die rymelaar tot vyand van die stryd

(Hugo, 1984:30).

Potlood en geweer, blyk dit dus, is onversoenbaar. Breekware vir die rewolusie sluit dan ook af met 'n gedig waarin rewolusie en digterskap dit teen vitale belange moet aflê:

die erdvark van ons stukkie aarde het hier by wyse van die gedig geweld en moord in hom verenig en digter en soldaat se waarde waar slegs wit kinders se vrese tel as anachronismes uitgespel

(Hugo, 1984:42).

Dis basies dieselfde insig as waartoe Breytenbach in die loop van die tyd gekom het, net helderder - en poeties meer funksioneel - geformuleer.

\section{Globale aard van die na-sestigse oorlogspoësie}

Die Afrikaanse oorlogspoësie na Sestig vertoon 'n kenmerk wat Hugo Friedrich in Die Struktur der modernen Lyrik (1967) as besonder karakteristiek van spesifiek 'moderne' poësie aandui: 'n paradoksale uiteenloop van eienskappe wat tog op 'n manier in ' $n$ kern saamhang. Aan die een kant tref ' $n$ mens daarin ' $n$ mineurstemming aan, aan die ander kant is heelwat van die materiaal in 'n speelse perspektief opgeneem, sonder dat dit die mineurgeaardheid van die materiaal ophef inteendeel: dit verskerp dit juis.

In al hierdie opsigte verskil dit globaalweg van die oorlogspoësie van voor Sestig ${ }^{2}$ - 'globaalweg': omdat verskillende digters van voor-Sestig in die na-Ses- 
tigerperiode bly voortskryf het, en buitendien vir sommige van die beste bydraes verantwoordelik is, soos D.J. Opperman, W.E.G. Louw en Ernst van Heerden.

Die oorlogspoësie van na Sestig práát basies, dit 'sing' nie. Jan Celliers kon nog vervoerd oor ' $n$ veldslag skryf, soos in sy bekende hulde aan 'n gevalle kryger:

Sy plek was voor, waar die blitsvure spat

uit die roers in die donkere lyn;

die vuur in sy oog is die ster van die dag, en die veer in sy hoed gaat ons voor soos 'n vlag ...

(“In memoriam", Nienaber \& Van den Heever, 1947)

Ook Toon van den Heever ("Ritrympie"), A.G. Visser ("Die jongste burger"), I.D. du Plessis ("Die rit van twee Boere" en "In memoriam") en Uys Krige ("Die rit van Jan Lafras Malherbe") kon nog meeslepend oor heldskap skryf. Waar die soldaat in die na-Sestigerpoësie hom in die greep van 'n meesleurende gees bevind, gaan dit om ' $n$ wrang, ironiese gees, soos in "Die stryd duur voort" van Etienne van Heerden (1987:85) waarin 'n maniese opmars teen "die bedreiging van die maan" gebeeld word.

Die speelse perspektief waarin oorlogsgegewens by digters soos Hennie Aucamp, André Letoit en in 'n mate Daniël Hugo opgeneem is, was nie iets heeltemal nuuts in die Afrikaanse oorlogspoësie nie. ' $n$ Mens het dit reeds by Leipoldt gekry, by name in "'n Nuwe liedjie op 'n ou deuntjie". In die na-Sestigerjare neem speelsheid egter ' $n$ veel ruimer plek in. Dit dien dieselfde doel as in Leipoldt se gedig: on die afgryslikheid van oorlog nog skrynender te laat deurskroei. Hierdie speelse perspektief is nie net tot die kabarette van Hennie Aucamp of André Letoit se "blues" beperk nie. 'n Hele aantal digters sit byvoorbeeld 'n spel op piekniek- en volksliedjies op tou, wat 'n ironiese gesprek met die makabere oorlogsgegewe tot gevolg het.

'n Belangrike rede waarom die poèsie na Sestig nie sing nie (behalwe in die pasgenoemde sin, dit wil sê ironies) maar praat, is dat die digters, gegee die besondere aard van die Suid-Afrikaanse oorlog, moreel stelling teenoor hul stof inneem. Dis in 'n belangrike mate stellingpoèsie, nie beeldingpoesie nie. Dis poësie wat eerder praat in die taal van die prosa as in dié van die poësie, op die minste nie van die tradisionele singvers nie.

'n Verskeidenheid kenmerke spruit hieruit voort. Heelwat gedigte voltrek hulle in tipiese prosaperiodes: selfstandige frases en sinne, dikwels sonder dat periodesnit en versreëlsnit saamval. Die maat is gevolglik dié van die prosaritme. Weinig gedigte het ' $n$ metriese gang, wat egter nie verrassend is nie: dis die funksionele pendant van die afwesigheid van 'n vervoerende loop waarna reeds verwys 
is. Die klankmateriaal word gekenmerk deur 'n skamelheid van rym en rymskemas. Die rym is in die algemeen insidenteel, selde skematies, en dan nie in die vorm van volrym nie, maar van 'gereduseerde' rym, soos assonansie, akkonsonansie, lettergreeprym, en derglike. Die somtotaal van dit alles is 'n onvoorspelbare, dikwels 'aggressiewe' melodiek. Die voorliefde is vir die vrye vers, sonder skematisering van versreêllengtes. Wanneer die materiaal van die gedig onderverdeel word, is die onderdele eerder versparagrawe as strofes. Daar is weinig beeldontginning, en dus ook weinig beeld-deurkomponering, soos mens dit voor-Sestigs aantref, byvoorbeeld by D.J. Opperman (in "Staking op die suikerplantasie, 1956") en Uys Krige (in "Lied van die Fascistiese bomwerpers", 1961). Dit gaan om beeldontploffing.

Daar is egter een tegniek uit die arsenaal van die skematiese poësie waarvan goeie gebruik gemaak word in na-Sestigerpoësie ... dit is die inskerpende refrein. Dis 'n middel wat goed saamgaan met stellingpoësie, in werklikheid funksioneel daarvoor is. Deur middel van die refrein kan die stelling(s) wat die gedig wil maak, 'ingehamer' word.

Die gebruik daarvan in na-Sestigerpoësie toon 'n wye spektrum: vanaf identieke herhaling (wat - natuurlik gegee die regte stof - die moontlikheid inhou om die mededeling wat in die refrein vervat is, te wysig, en wel: omdat die omgewing van die refrein telkens verander) tot 'n akkumulerende herhaling soos in die geval van "Herinnering van die teruggekeerde soldaat" van George Weideman (1987: 48 ), waarin die refrein die stelling wat die gedig maak, veelvoudig onderstreep.

Krige se "Lied van die Fascistiese bomwerpers" (1961:101) is 'n voorbeeld van hoe die oorlogspoësie van voor en na Sestig nie waterdig van mekaar geskei kan word nie. Dié vers bevat verskillende van die belangrikste kenmerke van die naSestigse oorlogsgedig. Dink byvoorbeeld aan die stellende aard daarvan, die voltrekking aan die hand van 'selfbeslote' frases (elke reël 'n frase), die variérende refrein. Maar dit het ook bygedra tot die ontwikkeling van 'n eiesoortige oorlogsgedig in die sestigerjare en daama. Dit geld die spel op ander gedigte, ook op ander oorlogsgedigte, waardeur die resonansieruimte van die verwysende gedig vergroot word. Die gedig of gedigte waama verwys word, help die gedig, soos in die geval van die refrein, om sy stelling te bevestig, dit as't ware te beedig. Die wêreld van die gedig word met behulp van die verwysingstegniek vergroot. Intertekstualiteit word dan ook op 'n skaal beoefen wat vroeër haas onbekend was in die Afrikaanse oorlogspoësie. Dit val terloops op hoe dikwels daar juis op Krige se gedig teruggespeel word (byvoorbeeld deur De Waal Venter, 1977, Annesu de Vos, 1980, en Johan de Jager, 1974), wat 'n hulde is aan die status wat dié gedig op die gebied van die Afrikaanse oorlogspoësie beklee. Ander gedigte wat meermale resonerend betrek word, is Van Wyk Louw se "Ignatius bid vir sy orde" ("Dat pyn bestaan, is nodig, Heer", 1954:12) en "Miskien ook sal ons sterwe" (1937:52) onder meer deur Breyten Breytenbach, 
wat die grondstellings daarvan argumenterend verwerp. Intertekstualiteit het aan die Afrikaanse oorlogspoësie iets minder eenlynigs en eensnarigs as dié van vroeër gegee.

Aan die ander kant is dit ook waar dat die stellingaard van baie van die na-Sestigse oorlogsgedigte hulle aan universaliteit laat inboet. Die gerigtheid op 'die saak' wat die gedig wil dien, staan die moontlikheid in die weg om sub specie aeternitatis na die gebeure te kyk, iets waarop die beste voor-Sestigse digters sterk gerig was en waarvan "Miskien ook sal ons sterwe" van Van Wyk Louw die kenmerkende voorbeeld is.

Waar intertekstualiteit so 'n opvallende rol in die na-Sestigse oorlogspoësie speel, verbaas dit nie dat ook ergosentrisme so opmerklik daarin aanwesig is. Terwyl die digter oor oorlog skryf, is hy hom deeglik daarvan bewus dat hy terselfdertyd 'n artefak, 'n gedig, aan die tot stand bring is. Ergosentrisme is wesentik 'n tug op 'saak'-ingesteldheid. Gedig en saak moet mekaar deurentyd in ag neem. In die geval van die geslaagde gedig blyk dit dat die wedersydse konsiderasie nie ' $n$ verlammende effek op die saak het nie, maar wel 'n vitaliserende. Die speelruimte van die gedig word deur ergosentrisme vergroot, en 'n weldadige spel van dubbelkantigheid word daardeur moontlik. Veral Daniël Hugo het getoon wat kan gebeur as "op papier lem tot lemma omgesmee word" (1984:37).

Ten spyte van die feit dat 'n nogal aansienlike hoeveelheid gedigte wat oor die oorlog geskryf is, slegs ' $n$ beperkte waarde het, veral vanweë die stelling-ingesteldheid daarvan en die daarmee gepaardgaande doel om 'met die bestel af te reken', het na-Sestigse oorlogspoësie 'n klein maar waardevolle getal goeie gedigte opgelewer wat die Afrikaanse poësie onteenseglik verryk het. Dit geld, wat die egte na-Sestigers betref, veral die werk van Etienne van Heerden, Wilma Stockenström en Danièl Hugo. Met "Die kind" van Ingrid Jonker en "Inbraak van die mamba" van Wilma Stockenström het die Afrikaanse poësie in elk geval twee klassieke gedigte bygekry.

\section{Bibliografie}

Botes, D.P.M 1973. Psalms van David. Johannesburg : Perskor

Breytenbach, B 1969. Koueviur. Kaapstad : Buren.

Breytenbach, B 1970. Oorblyfsels. Kaapstad: Buren.

Breytenbach, B. 1990. Soos die so. Amsterdam : Meulenhoff

De Jager, J. 1974. Haggada vir 'n wit Afrikaan Johannesburg : Perskor

De Vos, Annesu 1980. Gebed van'n groen perske en ander verse. Kaapstad: Tafelberg

De Vos, Annesu. 1982. Om vry uit te stap. Kaapstad: Tafelberg.

Friedrich, H. 1967. Die Struktur der modernen Lyrik. Hamburg : Rowohlt

Hugo, D. 1983. Buitekamerklanke Johannesburg : Perskor.

Hugo, D. 1984 Breekware vir die revolusie. Kaapstad : Human en Rousseau.

Krige, Uys. 1961. Gedigte 1927-1940. Pretoria : Van Schaik.

Letoit, A. 1988. Die bar op De Aar. Kaapstad: Tafelberg. 
Louw, N.P. van Wyk. 1937. Die halwe kring. Kaapstad : Nasionale Pers

Louw, N.P. van Wyk. 1954. Ninwe verse. Kaapstad : Nasionale Boekhandel.

Louw, W.E.G. 1972. Naggesprek en ander gedigte. Kaapstad: Tafelberg.

Louw, W.E.G. 1976. Vensters op die vrees. Kaapstad : Tafelberg.

Louw, W.E.G. 1980. Opvlugte en opdragte. Kaapstad : Tafelberg.

Marais, J.L. 1983 Die somer is 'n dag oud. Kaapstad : Human en Rousseau

Marais, J.L. 1989. By die dinge. Kaapstad: Human en Rousseau.

Nienaber, P.J. \& C.M. van den Heever 1947. Bloemlesing wit die gedigte van Jan F.E. Celliers. Johannesburg: APB.

Olivier, F. 1988 Verklarings 1967-1987. Kaapstad : Human en Rousseau.

Opperman, D.J. 1956. Blom en baaierd. Kaapstad : Nasionale Boekhandel

Philander, P.J. 1986 Ostrakon Johannesburg : Perskor.

Stockenstrom, Wilma. 1970. Vir die bysiende leser. Kaapstad : Reijger-uitgewers.

Stockenstrom, Wilma. 1973. Spieel van water. Kaapstad : Human en Rousseau.

Van Heerden, Ernst. 1987. Amulet teen die vuur. Kaapstad : Tafelberg.

Van Heerden, Etienne. 1981. Obiter dictum Kaapstad/Johannesburg : Perskor.

Van Rensburg, F.I.J. 1990. Digterlike berigte te velde: Die neerslag van oorlog in die Afrikaanse poesie tot Sestig. Acta Academict, 22(4):92-108, Desember.

Van Wyk, J 1981 Bome gaan dood om jou. Kaapstad : Human en Rousseau.

Venter, De Waal 1977. Reg? Tydskrif.vir Letterkunde, 15(1):30

Weideman, G.H. 1987. Uit hierdie grys verblyf. Kaapstad : Tafelberg.

\section{Randse Afrikaanse Universiteit}

